\title{
Is there anticipation in the age at onset of cancer in families with
}

\section{Li-Fraumeni syndrome?}

Received: February 19, 2002 / Accepted: April 15, 2002

\begin{abstract}
Anticipation in the age at onset of cancer in successive generations was described in several familial cancer syndromes. Based on multiple statistical analyses of a database of families with germline TP53 mutations, and using several different approaches and measures to eliminate possible biases, we show that anticipation may be a feature of the Li-Fraumeni syndrome. Definitive proof of anticipation in pedigrees with germline TP53 mutations will require more family data and further analysis, as well as research on the role of the $\mathrm{p} 53$ protein in processes like genome stability, which may represent the biological basis of anticipation in these families. This should have important practical implications for genetic testing, counselling, and preventative care for individuals at risk.
\end{abstract}

Key words Anticipation · Li-Fraumeni syndrome . Germline TP53 mutations - Age at onset - Hereditary cancer

\section{Introduction}

Anticipation is a phenomenon characterized by decreasing age at onset and/or increasing severity of symptoms of a disease in successive generations within a pedigree. Although it was viewed with skepticism for most of the last century as a possible result of ascertainment bias, the last decade has witnessed the recognition of trinucleotide repeat expansion as a molecular cause of this phenomenon in several human hereditary diseases (McInnis 1996). This has

M. Trkova $(\triangle) \cdot$ P. Goetz $\cdot$ Z. Sedlacek

Institute of Biology and Medical Genetics, Second Medical School, Charles University, V uvalu 84, 15006 Prague 5, Czech Republic

Tel. +420-2-24435991; Fax +420-2-24435994

e-mail: marie.trkova@LFMOTOL.cuni.cz

M. Hladikova $\cdot$ P. Kasal

Institute of Medical Informatics, Second Medical School, Charles

University, Prague, Czech Republic led to a renewed interest in the study of anticipation in a variety of inherited conditions. With the exception of triplet expansions, however, other possible genetic or biological mechanisms leading to anticipation are currently unexplored. The studies of anticipation are complicated because, in addition to real biological causes, the signs of anticipation may be attributed to several sampling and observation biases. These biases mainly include the tendency to select affected parents with late onset, affected offspring with early onset, and families with simultaneous onset of disease in parents and offspring (Fraser 1997).

Anticipation was reported recently in many familial cancer syndromes, including adenomatous polyposis coli (Presciuttini et al. 1994), ovarian cancer (Goldberg et al. 1997), breast cancer (Hsu et al. 2000), familial melanoma (Goldstein et al. 1996), pediatric neuroblastoma (Plon 1997), testicular cancer (Han and Peschel 2000), Hodgkin's and non-Hodgkin's lymphoma (Shugart et al. 2000; Wiernik et al. 2000), and several types of leukemia (Horwitz et al. 1996; Goldin et al. 1999). Because contradictory reports were also published providing no evidence of anticipation in some of these conditions, the issue remains controversial (Tsai et al. 1997; Paterson et al. 1999).

Li-Fraumeni syndrome is another well-recognized hereditary cancer syndrome. It is characterized by predisposition to a wide spectrum of tumors including sarcomas, breast cancer, brain tumors, leukemias, and other cancers ( $\mathrm{Li}$ and Fraumeni 1969). The syndrome is caused in most families by germline mutations in the tumor suppressor gene TP53 (Malkin et al. 1990; Srivastava et al. 1990). The possibility that anticipation shifts the age at onset of cancer to a younger age in succeeding generations in this syndrome was also mentioned in the literature, but the opinions are contradictory (Kleihues et al. 1997; Evans and Lozano 1997). Because of repeated observation of typical pedigree structures suggestive of anticipation in our own experience and because no analysis of a large set of Li-Fraumeni families has as yet been described, we performed a study of anticipation in the age at onset of the first tumor in 162 published cancer families. These families harbor germline TP53 mutations, were reported in the literature between 
1990 and 2000, and are listed in the Database of Germline p53 Mutations (Sedlacek et al. 1998). Our results lend credence to the notion that anticipation may indeed be a feature of the Li-Fraumeni syndrome.

\section{Subjects and methods}

\section{Set of families}

The December 2000 update of the Database of Germline p53 Mutations (Sedlacek et al. 1998, http://www.lf2.cuni.cz/ projects/germline_mut_p53.htm) was used as a source of the data. The database contained reports on 162 independent germline TP53 mutations in 162 families or isolated patients. In total, there were reports on 689 individuals (including 62 unaffected carriers) and 803 tumors. Of these, 549 individuals with known age at onset of the first tumor were included in the analysis. For analytical purposes, the youngest generation was always assigned the letter $\mathrm{Z}$ in each family in the database, the second-youngest generation was assigned $\mathrm{Y}$, the third-youngest generation was assigned $\mathrm{X}$, etc. The generational membership was, however, not fixed to the age at onset (for example, an isolated individual with tumor onset at 72 years was assigned generation $Z$ ). In case an individual suffered from more than one tumor during his or her lifetime, only the age at onset of the first tumor was considered.

Data were imported from the Excel table into an Access database system. Data relevant for each particular analytical approach were extracted from the Access tables and processed using the SPSS software package (Norusis 1994).

Comparison of the mean age at onset

between generations

Families were subdivided into five classes according to the number of generations reported for each family. The mean ages at onset for each generation were calculated separately for one-, two-, three-, four-, and five-generation families. In the same way, both sexes were then analyzed separately. Finally, two types of germline mutations (missense versus truncating [nonsense, frameshift, and splicing]) were also separately studied. The statistical significance of the differences in the mean age of onset between generations, between sexes, and between mutation types was tested using univariate analysis of variance, or analysis of variance with two factors, respectively. The significance of sex or mutation type differences in one-generation families was analyzed using the $t$-test.

Intergenerational pairwise comparisons of age at onset

To reduce potential sampling biases, we used four different sampling schemes for pairwise comparisons of the age at onset in two- to five-generation families (McInnis et al. 1993).
1. Random pairs consisted of one randomly selected affected individual from one generation and one randomly selected affected individual from the previous generation of the same family. This sampling is statistically conservative.

2. All possible pairs were formed by pairing each affected individual from one generation with all affected individuals from the previous generation within a family. Inclusion of childless individuals in schemes 1 and 2 reduces the bias from reduced fertility of severely affected family members, and scheme 2 tests for robustness of scheme 1 . By including affected siblings of parents of affected children, the study of nontransmitting pairs should reduce the spurious anticipation bias (Hoh et al. 2001).

3. Random transmitting pairs consisted of one randomly selected affected parent and one of his or her randomly selected affected children. This scheme is statistically conservative and represents the most direct test of anticipation.

4. All possible transmitting pairs were formed by pairing each affected parent with each of his or her affected children. Similar to the testing of scheme 2 for scheme 1 , scheme 4 tests for robustness of scheme 3 .

One pair was selected in schemes 1 and 3 from each two successive generations of a family. Pairs that included a child in which both parents were affected by a tumor (possible bilineal transmission) were excluded from schemes 3 and 4. Mean differences in ages at onset were calculated for the parent and offspring generations and compared using the Wilcoxon signed rank test.

All four schemes of pairwise comparisons were performed with the whole dataset and then with different subsets of data. First, only those pairs were included in which the age at onset in the offspring was after 25 years of age (subset offspring $>25$ years), to eliminate individuals with very early onset of cancer in the offspring generation (McInnis 1996). Second, pairs were only included in which the age at onset in the parent was less than 28.8 years (subset parent $<28.8$ years), which was the mean age at onset in the whole dataset. This measure was aimed at the elimination of ascertainment or observational bias (Han and Peschel 2000).

In addition, sampling schemes 3 and 4, using transmitting pairs, were applied to further data subsets. Pairs were separately analyzed in which the offspring belonged to generations $\mathrm{Y}, \mathrm{X}$, and $\mathrm{W}$ and the parent was affected at an age younger than 25, 50, and 75 years, respectively (subset generations 25 years). Considering intergeneration difference of 25 years, this selection should include pairs in which both the parent and his or her offspring were followed for the same time period (about 25, 50, and 75 years, respectively) (Imamura et al. 1998). To test for a possible effect of the mode of parental transmission on the difference in the age at onset, we separately analyzed pairs with female or male sex of the transmitting parent (subsets mothers, fathers). Similarly, we examined the data separately according to the sex of the offspring (subsets daughters, sons). The signifi- 
cance of the influence of sex of the parent or of the offspring on the difference in the age at onset between generations was analyzed using analysis of variance of repeated measures.

\section{Results}

Comparison of the mean age at onset between generations

The mean age at onset in different generations for the whole dataset is listed in Table 1 . The same calculation was also performed separately for males and females, and for missense and truncating mutations (data not shown). The mean age at onset of the first cancer is always lower in the generation of offspring than in the generation of parents for any two successive generations in any dataset, and the difference in the mean age at onset between generations in multiple-generation families is always highly significant $(P<0.0005)$. There is no significant difference in the age at onset between sexes for the one-, two-, three-, and fourgeneration families $(P=0.26,0.106,0.297$, and 0.265 , respectively). For the five-generation families, the sex difference is of borderline significance $(P=0.047)$, with the age at onset being higher in females. The set of data for fivegeneration families is not reliable, however, because of small numbers. Similarly, the influence of the mutation type on the age at onset is significant in one-generation families, with the truncating mutations being associated with earlier age at onset $(P=0.009)$, but there are only three mutations in this category among one-generation families. There is no significant difference in the age at onset of cancer and anticipation between mutation types for the two-, three-, and four-generation families $(P=0.619,0.070$, and 0.100 , respectively), although the trend of missense mutations being associated with later age at tumor onset than are truncating mutations can be repeatedly observed. There are no missense mutations in five-generation families.

Intergenerational pairwise comparisons of age at onset

The results of pairwise comparisons using sampling schemes 1-4 are listed in Tables 2-5. The fraction of pairs showing anticipation exceeds $50 \%$ for every sampling scheme and all subsets of data. Similarly, the mean age at

Table 1. Mean age at onset of the first tumor in different generations

\begin{tabular}{|c|c|c|c|c|c|c|}
\hline & & \multicolumn{5}{|l|}{ Generation } \\
\hline & & V & $\mathrm{W}$ & $\mathrm{X}$ & $\mathrm{Y}$ & $\mathrm{Z}$ \\
\hline $\begin{array}{l}\text { One-generation } \\
\text { families } \\
(N=40)\end{array}$ & $\begin{array}{l}\text { No. of subjects }{ }^{\mathrm{a}} \\
\text { Mean age at onset } \pm \mathrm{SE} \text { (years) } \\
\text { Mean age difference } \pm \mathrm{SE} \text { (years) }\end{array}$ & $\begin{array}{l}- \\
-\end{array}$ & $\begin{array}{l}- \\
-\end{array}$ & $\begin{array}{l}- \\
-\end{array}$ & - & $\begin{array}{l}37 \\
21.8 \pm 3.2 \\
\text { n.a. }\end{array}$ \\
\hline $\begin{array}{l}\text { Two-generation } \\
\text { families } \\
(N=55)\end{array}$ & $\begin{array}{l}\text { No. of subjects }{ }^{\mathrm{a}} \\
\text { Mean age at onset } \pm \text { SE (years) } \\
\text { Mean age difference } \pm \text { SE (years) }\end{array}$ & $\begin{array}{l}- \\
-\end{array}$ & $\begin{array}{l}- \\
-\end{array}$ & $\begin{array}{l}- \\
- \\
-\end{array}$ & $\begin{array}{l}75 \\
40.0 \pm 2.0 \\
\text { n.a. }\end{array}$ & $\begin{array}{l}76 \\
13.2 \pm 1.5 \\
26.5 \pm 2.7\end{array}$ \\
\hline $\begin{array}{l}\text { Three-generation } \\
\text { families } \\
(N=51)\end{array}$ & $\begin{array}{l}\text { No. of subjects }{ }^{\mathrm{a}} \\
\text { Mean age at onset } \pm \mathrm{SE} \text { (years) } \\
\text { Mean age difference } \pm \mathrm{SE}(\text { years) }\end{array}$ & $\begin{array}{l}- \\
-\end{array}$ & - & $\begin{array}{l}60 \\
47.8 \pm 2.1 \\
\text { n.a. }\end{array}$ & $\begin{array}{l}82 \\
34.5 \pm 1.6 \\
13.8 \pm 2.5\end{array}$ & $\begin{array}{l}85 \\
15.3 \pm 1.4 \\
18.3 \pm 2.3\end{array}$ \\
\hline $\begin{array}{l}\text { Four-generation } \\
\text { families } \\
(N=13)\end{array}$ & $\begin{array}{l}\text { No. of subjects }{ }^{\mathrm{a}} \\
\text { Mean age at onset } \pm \text { SE (years) } \\
\text { Mean age difference } \pm \text { SE (years) }\end{array}$ & - & $\begin{array}{l}14 \\
46.7 \pm 4.6 \\
\text { n.a. }\end{array}$ & $\begin{array}{l}29 \\
35.9 \pm 2.9 \\
11.8 \pm 4.9\end{array}$ & 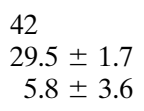 & $\begin{array}{l}23 \\
14.7 \pm 3.6 \\
14.9 \pm 3.8\end{array}$ \\
\hline $\begin{array}{l}\text { Five-generation } \\
\text { families } \\
(N=3)\end{array}$ & $\begin{array}{l}\text { No. of subjects } \\
\text { Mean age at onset } \pm \text { SE (years) } \\
\text { Mean age difference } \pm \text { SE (years) }\end{array}$ & $\begin{array}{l}2 \\
45.0 \pm 5.0 \\
\text { n.a. }\end{array}$ & $\begin{array}{l}5 \\
49.2 \pm 4.7 \\
10.4 \pm 8.8\end{array}$ & $\begin{array}{c}7 \\
32.7 \pm 2.9 \\
19.7 \pm 6.0\end{array}$ & $\begin{array}{l}9 \\
15.6 \pm 4.6 \\
12.1 \pm 5.5\end{array}$ & $\begin{array}{l}3 \\
9.3 \pm 3.5 \\
3.9 \pm 6.7\end{array}$ \\
\hline
\end{tabular}

n.a., Not applicable

${ }^{a}$ Only individuals with known age of onset are listed

${ }^{\mathrm{b}}$ Mean age difference to the preceding generation

Table 2. Intergenerational pairwise comparisons of age at onset of the first tumor using sampling scheme 1 (random pairs)

\begin{tabular}{llll}
\hline & $\begin{array}{l}\text { Whole } \\
\text { dataset }\end{array}$ & $\begin{array}{l}\text { Offspring } \\
>25 \text { years }\end{array}$ & $\begin{array}{l}\text { Parent } \\
<28.8 \text { years }\end{array}$ \\
\hline Total no. of pairs & 158 & 65 & 37 \\
No. (\%) of pairs with anticipation & $135(85.4 \%)$ & $50(76.9 \%)$ & $25(67.6 \%)$ \\
Mean age at onset in parent \pm SE (years) & $39.3 \pm 1.3$ & $50.7 \pm 1.8$ & $19.1 \pm 1.3$ \\
Mean age at onset in offspring \pm SE (years) & $21.8 \pm 1.4$ & $38.9 \pm 1.4$ & $10.1 \pm 1.5$ \\
Mean difference in age at onset \pm SE (years) & $17.5 \pm 1.2$ & $11.9 \pm 1.8$ & $9.1 \pm 1.9$ \\
P & $<0.0005$ & $<0.0005$ & $<0.0005$ \\
$Z$ & -9.8 & -5.2 & -3.9 \\
\hline
\end{tabular}


Table 3. Intergenerational pairwise comparisons of age at onset of the first tumor using sampling scheme 2 (all possible pairs)

\begin{tabular}{lllc}
\hline & $\begin{array}{l}\text { Whole } \\
\text { dataset }\end{array}$ & $\begin{array}{l}\text { Offspring } \\
>25 \text { years }\end{array}$ & $\begin{array}{l}\text { Parent } \\
<28.8 \text { years }\end{array}$ \\
\hline Total no. of pairs & 699 & 307 & 181 \\
No. (\%) of pairs with anticipation & $561(80.3 \%)$ & $201(65.5 \%)$ & $97(53.6 \%)$ \\
Mean age at onset in parent \pm SE (years) & $37.5 \pm 0.6$ & $43.5 \pm 0.9$ & $19.7 \pm 0.5$ \\
Mean age at onset in offspring \pm SE (years) & $23.1 \pm 0.6$ & $37.9 \pm 0.5$ & $17.5 \pm 1.0$ \\
Mean difference in age at onset \pm SE (years) & $14.3 \pm 0.6$ & $5.5 \pm 0.9$ & $2.1 \pm 1.1$ \\
P & $<0.0005$ & $<0.0005$ & 0.037 \\
Z & -17.5 & -5.8 & -2.1 \\
\hline
\end{tabular}

Table 4. Intergenerational pairwise comparisons of age at onset of the first tumor using sampling scheme 3 (random transmitting pairs)

\begin{tabular}{|c|c|c|c|c|c|c|}
\hline & $\begin{array}{l}\text { Whole } \\
\text { dataset }\end{array}$ & $\begin{array}{l}\text { Offspring } \\
>25 \text { years }\end{array}$ & $\begin{array}{l}\text { Parent } \\
<28.8 \text { years }\end{array}$ & $\begin{array}{l}\text { Generations } \\
25 \text { years }\end{array}$ & Mothers & Fathers \\
\hline Total no. of pairs & 150 & 62 & 27 & 11 & 95 & 54 \\
\hline No. $(\%)$ of pairs with anticipation & $135(90.0 \%)$ & $48(77.4 \%)$ & $22(81.5 \%)$ & $8(72.7 \%)$ & $85(89.5 \%)$ & $49(90.7 \%)$ \\
\hline Mean age at onset in parent $\pm \mathrm{SE}$ (years) & $40.7 \pm 1.1$ & $48.5 \pm 1.9$ & $23.6 \pm 1.1$ & $40.3 \pm 3.4$ & $39.4 \pm 1.3$ & $42.9 \pm 2.2$ \\
\hline Mean age at onset in offspring $\pm \mathrm{SE}$ (years) & $22.0 \pm 1.4$ & $39.2 \pm 1.4$ & $11.3 \pm 2.3$ & $31.5 \pm 6.2$ & $21.9 \pm 1.8$ & $21.7 \pm 2.2$ \\
\hline Mean difference in age at onset \pm SE (years) & $18.7 \pm 1.3$ & $9.4 \pm 2.1$ & $12.3 \pm 2.3$ & $8.8 \pm 4.7$ & $17.5 \pm 1.6$ & $21.3 \pm 2.1$ \\
\hline $\begin{array}{l}P \\
Z\end{array}$ & $\begin{array}{l}<0.0005 \\
-9.5\end{array}$ & $\begin{array}{l}<0.0005 \\
-4.1\end{array}$ & $\begin{array}{l}<0.0005 \\
-3.8\end{array}$ & $\begin{array}{l}0.09 \\
-1.7\end{array}$ & $\begin{array}{l}<0.0005 \\
-7.4\end{array}$ & $\begin{array}{l}<0.0005 \\
-6.0\end{array}$ \\
\hline
\end{tabular}

Table 5. Intergenerational pairwise comparisons of age at onset of the first tumor using sampling scheme 4 (all possible transmitting pairs)

\begin{tabular}{|c|c|c|c|c|c|c|}
\hline & $\begin{array}{l}\text { Whole } \\
\text { dataset }\end{array}$ & $\begin{array}{l}\text { Offspring } \\
>25 \text { years }\end{array}$ & $\begin{array}{l}\text { Parent } \\
<28.8 \text { years }\end{array}$ & $\begin{array}{l}\text { Generations } \\
25 \text { years }\end{array}$ & Mothers & Fathers \\
\hline Total no. of pairs & 264 & 119 & 41 & 26 & 167 & 95 \\
\hline No. $(\%)$ of pairs with anticipation & $226(85.6 \%)$ & $83(69.8 \%)$ & $29(70.7 \%)$ & $18(69.2 \%)$ & $142(85.0 \%)$ & $82(86.3 \%)$ \\
\hline Mean age at onset in parent \pm SE (years) & $40.8 \pm 0.8$ & $46.4 \pm 1.2$ & $24.1 \pm 0.9$ & $39.5 \pm 1.7$ & $39.8 \pm 0.9$ & $42.5 \pm 1.5$ \\
\hline Mean age at onset in offspring $\pm \mathrm{SE}$ (years) & $24.1 \pm 1.0$ & $39.4 \pm 0.9$ & $15.3 \pm 2.2$ & $32.7 \pm 2.9$ & $24.6 \pm 1.3$ & $23.1 \pm 1.6$ \\
\hline Mean difference in age at onset \pm SE (years) & $16.7 \pm 1.0$ & $7.0 \pm 1.3$ & $8.7 \pm 2.1$ & $6.8 \pm 2.6$ & $15.3 \pm 1.2$ & $19.4 \pm 1.7$ \\
\hline $\begin{array}{l}P \\
Z\end{array}$ & $\begin{array}{l}<0.0005 \\
-12.2\end{array}$ & $\begin{array}{l}<0.0005 \\
-4.8\end{array}$ & $\begin{array}{l}<0.0005 \\
-3.6\end{array}$ & $\begin{array}{l}0.024 \\
-2.26\end{array}$ & $\begin{array}{l}<0.0005 \\
-9.5\end{array}$ & $\begin{array}{l}<0.0005 \\
-7.6\end{array}$ \\
\hline
\end{tabular}

onset in the offspring is always lower than that in the parent. As expected, both the fraction of pairs showing anticipation and the mean difference in the age at onset between generations decrease in subsets offspring $>25$ years, parent $<28.8$ years, and generations 25 years compared with the whole unselected dataset. The difference is always statistically significant with the exception of subset generations 25 years in scheme $3(P=0.09)$. The age difference in subset generations 25 years in scheme 4 is weakly significant $(P=0.024)$. The subset generations 25 years consists, however, of a very small number of pairs in each of these two schemes (11 and 26 , respectively).

In addition, the transmitting pairs were analyzed separately according to the sex of the parent (subsets mothers, fathers, Tables 4-5) or sex of the child (subsets daughters, sons, data not shown). The fraction of pairs showing anticipation always exceeds $50 \%$ and the mean difference in age at onset in the offspring and in the parent is always highly significant. For random transmitting pairs, no significant influence of either the sex of the parent or the sex of the child on the mean difference in the age at onset between generations was found. For all possible transmitting pairs, significant influence of the sex of the parent on the mean difference in the age at onset was found $(P=0.039)$, with the paternal transmission associated with increased mean age difference between generations (Table 5). No influence of the sex of the offspring on the mean difference in the age at onset was found.

\section{Discussion}

A significant decrease in the age at onset of cancer between successive generations in pedigrees with germline TP53 mutations was demonstrated in this study. This was ob- 
served not only for the mean ages at onset calculated for different generations, but also in different schemes of pairwise comparisons. Our analyses therefore suggest the existence of anticipation resulting in increasingly earlier age at onset of cancer in successive generations of carriers of germline TP53 mutations.

We attempted to minimize all possible biases by using multiple analytical approaches, several sampling schemes, and separate analyses of several subsets of data selected using various conservative assumptions. One possible ascertainment bias is the underrepresentation of families with early-onset cases (before reaching the reproductive age) in the older generation and late occurrence in the younger generation because of reduced fertility in the older generation. To avoid this bias, we removed all individuals with onset under the age of 25 years from the offspring generation and repeated the statistical analysis (subset offspring $>$ 25 years). Within this subset, the conditions for both generations are more comparable. To further reduce the bias resulting from impaired fertility, we examined not only the parent-offspring pairs, but also the nontransmitting pairs (random pairs, all possible pairs) (McInnis 1996; McInnis et al. 1993).

To avoid the underrepresentation of families with earlyonset cases in the older generation and late-onset cases in the younger generation because of the time of ascertainment being too short for the younger generation to develop symptoms, we also performed the analysis for a subset of individuals in which the age at diagnosis in the parents was less than the mean age at onset in the whole dataset (subset parent $<28.8$ years) (Han and Peschel 2000). In an even more stringent selection of pairs for the analysis (generations 25 years), we selected only those transmitting pairs in which the offspring belonged to generation $\mathrm{Y}$ ( or X, or W) and the age at onset in the parent was less than 25 years (or 50 , or 75 years, respectively) (Imamura et al. 1998). Assuming an intergeneration span of 25 years, the offspring can be expected to be followed for at least 25 (or 50 , or 75 years, respectively), and this time is longer than the age at onset of cancer in the parents.

All subsets tested showed similar patterns suggestive of anticipation in the age of cancer onset in the pedigrees, and the age differences were statistically significant. Even in the most stringent subset generations 25 years, in which the number of pairs was only 11 and 26 for random transmitting pairs and all possible transmitting pairs, respectively, the difference remained near significant (Tables 4-5).

Another possible bias that may mimic anticipation can result from shared environmental factors. We consider this less likely because the affected individuals within and between families in the dataset are widely distributed geographically and across time. Bilineality is unambiguously proven at the molecular level only in one family in the database and its possible influence was suppressed by the exclusion of all offspring with both parents affected from the pairwise comparisons. Possible preferential reporting of families with simultaneous onset in a parent and his or her offspring or of families with unusually early onset in the child and the fact that our study is based on published reports rather than on a regularly updated registry represent two additional potential biases. To avoid all biases completely, one would need a prospectively obtained case study on a very large population over a period of several generations (Wiernik et al. 2000). Such a study is rather impractical, however, because of the very low incidence of the disorder and the length of the time period required. Additionally, the Li-Fraumeni syndrome was recognized as late as 1968, and germline TP53 mutations were recognized as the etiological cause of the disorder only in 1990.

Our study is a first attempt to statistically evaluate the suspected anticipation in the Li-Fraumeni syndrome. However, further data collection and analyses are needed to decide unambiguously about this phenomenon. If anticipation in age at onset really exists in the pedigrees carrying germline TP53 mutations, it should be based on a biological mechanism involving the p53 protein. It is tempting to speculate that this mechanism might be related to the recently recognized role of p53 in genome stability (ArandaAnzaldo et al. 1999; Murphy et al. 2000; Lin et al. 2000; Dahm-Daphi 2000). The gain-of-function germline mutations and/or reduced dosage of the normal TP53 gene expression might cause some kind of cumulative damage to the genome of the cells in the germ line, which could then result in an even more increased level of susceptibility to cancer in successive generations. Indeed, it will only be the identification and deciphering of such a biological mechanism that will definitively solve the question of anticipation in this disorder.

If anticipation in Li-Fraumeni syndrome is unambiguously proven, this will have important practical consequences for genetic counselling and testing and for the timing of preventative screening programs for individuals at risk. According to the present recommendations for the care of affected families, testing of young children should not be offered routinely ( $\mathrm{Li}$ et al. 1992; Varley et al. 1997). Furthermore, possible influence of paternal or maternal transmission or the type of mutation on the age at onset in the offspring cannot be fully excluded.

Acknowledgments We thank Nina Heiss for critical reading of the manuscript. The study was supported by grants No. NC/6513-3, 111300003 , and J12/2000 from the Ministry of Health and the Ministry of Education of the Czech Republic.

\section{References}

Aranda-Anzaldo A, Orozco-Velasco F, Garcia-Villa E, Gariglio P (1999) p53 is a rate-limiting factor in the repair of higher-order DNA structure. Biochim Biophys Acta 1446:181-192

Dahm-Daphi J (2000) p53: biology and role for cellular radiosensitivity. Strahlenther Onkol 176:278-285

Evans SC, Lozano G (1997) The Li-Fraumeni syndrome: an inherited susceptibility to cancer. Mol Med Today 3:390-395

Fraser FC (1997) Trinucleotide repeats not the only cause of anticipation. Lancet 350:459-460

Goldberg JM, Piver MS, Jishi MF, Blumenson L (1997) Age at onset of ovarian cancer in women with a strong family history of ovarian cancer. Gynecol Oncol 66:3-9 
Goldin LR, Sgambati M, Marti GE, Fontaine L, Ishibe N, Caporaso N (1999) Anticipation in familial chronic lymphocytic leukemia. Am J Hum Genet 65:265-269

Goldstein AM, Clark WH Jr, Fraser MC, Tucker MA (1996) Apparent anticipation in familial melanoma. Melanoma Res 6:441-446

Han S, Peschel RE (2000) Father-son testicular tumors: evidence for genetic anticipation? A case report and review of the literature. Cancer 88:2319-2325

Hoh J, Heitjan DF, Merette C, Ott J (2001) Ascertainment and anticipation in family studies. Hum Hered 51:23-26

Horwitz M, Goode EL, Jarvik GP (1996) Anticipation in familial leukemia. Am J Hum Genet 59:990-998

Hsu L, Zhao LP, Malone KE, Daling JR (2000) Assessing changes in ages at onset over successive generation: an application to breast cancer. Genet Epidemiol 18:17-32

Imamura A, Honda S, Nakane Y, Okazaki Y (1998) Anticipation in Japanese families with schizophrenia. J Hum Genet 43:217-223

Kleihues P, Schauble B, zur Hausen A, Esteve J, Ohgaki H (1997) Tumors associated with p53 germline mutations: a synopsis of 91 families. Am J Pathol 150:1-13

Li FP, Fraumeni JF (1969) Rhabdomyosarcoma in children: epidemiologic study and identification of a familial cancer syndrome. J Natl Cancer Inst 43:1365-1373

Li FP, Garber JE, Friend SH, Strong LC, Patenaude AF, Juengst ET, Reilly PR, Correa P, Fraumeni JF Jr (1992) Recommendations on predictive testing for germ line p53 mutations among cancer-prone individuals. J Natl Cancer Inst 84:1156-1160

Lin X, Ramamurthi K, Mishima M, Kondo A, Howell SB (2000) p53 interacts with the DNA mismatch repair system to modulate the cytotoxicity and mutagenicity of hydrogen peroxide. Mol Pharmacol 58:1222-1229

Malkin D, Li FP, Strong LC, Fraumeni JF, Nelson CE, Kim DH, Kassel J, Gryka MA, Bischoff FZ, Tainsky MA, Friend SH (1990) Germ line p53 mutations in a familial syndrome of breast cancer, sarcomas, and other neoplasms. Science 250:1233-1238

McInnis MG (1996) Anticipation: an old idea in new genes. Am J Hum Genet 59:973-979
McInnis MG, McMahon FJ, Chase GA, Simpson SG, Ross CA, DePaulo JR Jr (1993) Anticipation in bipolar affective disorder. Am J Hum Genet 53:385-390

Murphy KL, Dennis AP, Rosen JM (2000) A gain of function p53 mutant promotes both genomic instability and cell survival in a novel p53-null mammary epithelial cell model. FASEB J 14:22912302

Norusis MJ (1994) SPSS Advanced Statistics 6.1. SPSS Inc., Chicago

Paterson AD, Naimark DM, Huang J, Vachon C, Petronis A, King RA, Anderson VE, Sellers TA (1999) Genetic anticipation and breast cancer: a prospective follow-up study. Breast Cancer Res Treat 55:21-28

Plon SE (1997) Anticipation in pediatric malignancies. Am J Hum Genet 60:1256-1257

Presciuttini S, Varesco L, Sala P, Gismondi V, Rossetti C, Bafico A, Ferrara GB, Bertario L (1994) Age of onset in familial adenomatous polyposis: heterogeneity within families and among APC mutations. Ann Hum Genet 58:331-342

Sedlacek Z, Kodet R, Poustka A, Goetz P (1998) A database of germline p53 mutations in cancer-prone families. Nucleic Acids Res 26:214-215

Shugart YY, Hemminki K, Vaittinen P, Kingman A, Dong C (2000) A genetic study of Hodgkin's lymphoma: an estimate of heritability and anticipation based on the familial cancer database in Sweden. Hum Genet 106:553-556

Srivastava S, Zou ZQ, Pirollo K, Blattner W, Chang EH (1990) Germline transmission of a mutated p53 gene in a cancer-prone family with Li-Fraumeni syndrome. Nature 348:747-749

Tsai YY, Petersen GM, Booker SV, Bacon JA, Hamilton SR, Giardiello FM (1997) Evidence against genetic anticipation in familial colorectal cancer. Genet Epidemiol 14:435-446

Varley JM, Evans DG, Birch JM (1997) Li-Fraumeni syndrome - a molecular and clinical review. Br J Cancer 76:1-14

Wiernik PH, Wang SQ, Hu XP, Marino P, Paietta E (2000) Age of onset evidence for anticipation in familial non-Hodgkin's lymphoma. Br J Haematol 108:72-79 